\title{
Understanding Juvenile Offending Trajectories
}

Michael Livingston, Anna Stewart, Troy Allard and James Ogilive

School of Criminology and Criminal Justice

Griffith University

Address for Correspondence

Anna Stewart

School of Criminology and Criminal Justice

Mt Gravatt Campus

Griffith University

Brisbane, Queensland, 4111

Email: A.Stewart@griffith.edu.au

Word Count: 6,700 


\begin{abstract}
A considerable amount of international research has adopted a criminal careers framework to improve our understanding of offending patterns across the life course. Recent innovations in statistical modelling techniques such as Semi-Parametric Group-based Method (SPGM) have provided researchers with tools to model offending trajectories. While this framework and these techniques may improve our understanding of life course offending patterns, few Australian studies have adopted such an approach. SPGM was employed in the current study to model the offending patterns of the 1983-84 Queensland offender cohort $(n=4,470)$ to address three research questions: (i) How many distinct offending trajectories could be identified and what was the nature of these trajectories? (ii) How were sex, Indigenous status, socio-economic disadvantage, and remoteness related to offending trajectory membership? and (iii) Are juvenile offending trajectories predictors of adult offending? Findings indicated that there were three distinct groups of juvenile offenders: Early Peaking-Moderate Offenders, Late Onset-Moderate Offenders, and Chronic Offenders. Males and Indigenous offenders were over-represented in the chronic offending trajectory. Support for the utility of the model was found, as Chronic Offenders were more likely to have offended as adults. The theoretical and practical implications of these findings are discussed and the need for further trajectory research within an Australian context is emphasised.
\end{abstract}




\section{Introduction}

The criminal careers framework has been extensively used in the international literature to improve our understanding of offending patterns over the developmental lifecourse (Blumstein, Cohen, Roth, \& Visher, 1986; Cain, 1997; Carcach \& Leverett, 1999; Chen, Matruglio, Weatherburn, \& Hua, 2005; Farrington, 2003a; Lynch, Buckman, \& Krenske, 2003; Marshall, 2006; Piquero, Farrington, \& Blumstein, 2003a). This framework is concerned with continuity and change in the nature and pattern of criminality over time, including onset or initiation, termination or desistence, and duration or career length of

offending (Blumstein, Cohen, \& Farrington, 1988; Farrington \& West, 1990). More recently, Developmental and Life-course Criminology (DLC) has extended the notion of criminal careers to include exploration of how the dynamic nature of risk factors or changes that occur over the life-course are related to particular offending pathways (Farrington, 2003b; National Crime Prevention, 1999).

DLC attempts to understand the development of offending and antisocial behaviour, risk factors across different ages, and the effects of life events on the course of development (Farrington, 2003b). Broadly speaking, developmental approaches view the life course as a series of phases, a series of points of change, a series of transitions, rather than a fixed progression towards adulthood determined by factors early in life (Elder, 1994; National Crime Prevention, 1999). This approach focuses on pathways with a multitude of outcomes, and aspects of time and timing of life events and transition points in order to understand developmental outcomes (Elder, 1994; National Crime Prevention, 1999). 
Importantly, the approach has the potential to inform research on offending behaviour, including the differences over time both within and between individuals, in an effort to understand both how and when to intervene (Carcach \& Leverett, 1999; Marshall, 2006).

A developmental trajectory refers to a pathway of development over the life course relating to long-term patterns and sequences of behaviour (Nagin \& Tremblay, 2005; Sampson \& Laub, 2005). The analysis of developmental trajectories in such fields as criminology and psychopathology provides researchers with the ability to understand the development of normative and non-normative behaviour over the life course. It allows researchers to examine the pathways of adaptation and non-adaptation that individuals follow to arrive at particular outcomes (Chung, Hill, Hawkins, Gilchrist \& Nagin, 2002; Kokko, Tremblay, Lacourse, Nagin \& Vitaro, 2006; Wiesner, Kim \& Capaldi, 2005). Recent innovations in statistical modelling techniques, including Semi-Parametric Group-based Modelling (SPGM; Nagin, 1999; Nagin \& Land, 1993), and Latent Growth Mixture Modelling (LGMM; Muthén \& Muthén, 2000) have provided DLC researchers with the tools to model heterogeneity and homogeneity across offending trajectories (Kreuter \& Muthén, 2008; Nagin \& Tremblay, 1999; Wiesner, et al., 2005). Such developments are vital to advance our knowledge of the factors associated with different offending trajectories across different points in the life-course.

The present study applied SPGM to model the juvenile offending trajectories of an Australian offender cohort, as comparatively few Australian studies have adopted criminal career or life-course perspectives to examine offending patterns longitudinally (for 
example, see Marshall, 2006). In Australia, understanding the offending careers of Indigenous young people is central to understanding juvenile offending. This study examined the relationships among Indigenous status and gender, while controlling for socio-economic status and remoteness, and juvenile offending trajectories. Finally, the relationship between the juvenile offending trajectories and offending as a young adult was explored.

\section{Theoretical Debates}

Within the DLC perspective, there exists significant diversity in theoretical models and debate among them in terms of how best to account for continuity and change in antisocial behaviour over the lifespan, known as the age-crime debate (Brame, Bushway, Paternoster, \& Thornberry, 2005; Farrington, 2003b; Nagin \& Paternoster, 2000; Paternoster, Dean, Piquero, Mazerolle \& Brame, 1997; Sampson \& Laub, 2003). This has led to debate over whether the predictors of offending have uniform or specific effects across different offending trajectories at different points during development (Chung et al., 2002; Farrington, 2003b).

One of the most significant debates is between theories emphasising population heterogeneity and those emphasising state dependence explanations (Brame et al., 2005; Nagin \& Paternoster, 2000; Paternoster et al., 1997). Both types of theories attempt to explain the robust criminological finding of a moderately strong positive association between past and future criminality, where individuals with prior offences are much more 
likely to commit future offences when compared to those with no prior offences (Nagin \& Paternoster, 2000).

Population heterogeneity theories conceptualise the continuity in criminality as a static process, where continuity in criminal behaviour is the result of a common time-stable underlying propensity or proneness to commit crime that is established early in life (Cernkovich \& Giordano, 2001; Nagin \& Paternoster, 2000; Paternoster et al., 1997). Gottfredson and Hirschi's (1990) self-control theory, where it is argued that the propensity for criminality (low self-control) is established early in life, is time-stable, differs in intensity across individuals in a population, and operates as a function of age to produce desistance from crime naturally.

In contrast, state dependence theories conceptualise continuity in criminality as a dynamic process, where continuity is a result of a process of contagion, when criminal or noncriminal behaviour transforms life conditions and alters the probability of future offending (Nagin \& Paternoster, 2000). This view emphases the variable nature of criminality over time and the cumulative effects that various factors may have on offending at different points in the life course (Cernkovich \& Giordano, 2001; Ezell, 2007; Nagin \& Paternoster, 2000; Williams \& Arnold, 2002). An example of a state dependence theory is Thornberry’s (2005) interactional theory, which emphasises the importance of social controls in determining antisocial behaviour. The theory argues that involvement in criminal behaviour weakens one's attachments to prosocial individuals and institutions, which in turns leads to an increased probability of future criminal behaviour (Thornberry, 2005). 
Theoretical explanations of the continuity and change in criminal behaviour may integrate both population heterogeneity and state dependence perspectives, where differences in continuity and change of antisocial behaviour may be explained by both differences in antisocial propensities and the cumulative effects of past experiences on present and future behaviour (Brame et al., 2005; Nagin \& Paternoster, 2000). Sampson and Laub’s (1993, 2003a, 2005) age-graded theory of social control is an example of an integrated theory. They assert that crime is more likely to occur when an individual's bond to society is attenuated, that is, when informal social control is lacking. The dynamic nature of informal social controls means that they exert their influences on behaviour to varying extents at different stages of the life-course and interact with individual propensities to engage in criminal behaviour (Sampson \& Laub, 2005).

An example of a multiple pathway theory that adopts both a static and dynamic causal view of criminal behaviour is Moffitt's $(1993,1997)$ taxonomy that proposes two distinct theoretical explanations of the etiological foundations of different offending patterns. She argues that there exist two trajectories of individuals embedded within the curve of crime over age, being the Adolescent Limited (AL) Type and the Life-Course Persistent (LCP) Type (Moffitt, 1993, 1997). AL offenders are characterised by temporary offending patterns believed to be caused by proximal factors beginning at puberty and ending in young adulthood, where their criminal behaviour is hypothesised to be normative and lack continuity, with discontinuity the hallmark of their criminal careers (Moffitt, 1993, 1997). LCP offenders are a small group of high rate offenders characterised by substantial 
continuity in antisocial behaviour over time, such that their antisocial behaviour is manifest at an early age (Moffitt, 1993, 1997). The etiological basis for LCP offending is argued to be factors capable of producing differences in neuropsychological functioning of the infant nervous system, resulting in deficits in temperament, behavioural and cognitive development (Moffitt, 1993, 1997, 2006). Such deficits are argued to set in motion a lifetime of negative reciprocal exchanges between the individual and the social environment, consolidating their antisocial behaviour (Moffitt, 1993, 1997, 2006).

The growing body of empirical evidence examining the continuity and change in criminal behaviour over the life-course indicates that the effects of both individual differences in criminal propensity and individual life events and experiences after controlling for criminal propensity are vital factors in understanding criminal behaviour and desistance from offending (Brame et al., 2005; Nagin \& Paternoster, 2000). Thus, the available evidence supports a mixed model of the development of offending over the life-course. These theoretical developments have lead to the development of statistical models for analysing longitudinal data and exploring the theoretical issues regarding explanations of the development, continuity and discontinuity of crime over the life-course. Currently there are two dominant models in the literature - conventional growth curve models and groupbased trajectory models (Kreuter \& Muthén, 2008). Conventional growth models assume normality of the growth factors, an assumption challenged by Nagin and Land (1993). Nagin and Land (1993) proposed a modelling technique, Semi-Parametric Group-based Method (SPGM) that identifies different groups, each with their own trajectory, to capture the variation in the data (Kreuter \& Muthén, 2008; Piquero, 2008). This technique has been 
used to examine the heterogeneity and homogeneity among offenders and for identifying the number of groups following distinct developmental pathways.

Piquero (2008) reviewed over 80 studies that employed trajectory analysis. These studies varied considerably in sample characteristics, age ranges, length of follow-up measures, and analytic strategies and decisions. However, Piquero (2008) drew four main conclusions from offender-based trajectory studies. First, consistent with Moffit’s (1993) taxonomic theory, the empirical research does identify at least two offender groups; an adolescent-peaked pattern and a chronic offender pattern. Interestingly, contrary to theoretical predictions, trajectory analyses also typically identify a late-onset chronic group. This group begins offending during adolescence and continues offending into adulthood. Second, the trajectory method consistently identifies between three and five offending groups, slightly more in studies using self-reports of offending behaviour rather than official records. Third, samples sizes greater than 500 provide robust categorisation of groups. Finally, there tends to be a low rate group, a high rate group and a moderate but declining group.

Sex has been found to be related to trajectory group membership (Broidy et al., 2003; Chung et al., 2002; Fergusson \& Horwood, 2002; Piquero et al., 2005). While little is known concerning the developmental patterns of female offending across the life-course (Cernkovich \& Giordano, 2001; Piquero, Brame, \& Moffitt, 2005) the following studies have indicated that trajectory analyses can contribute to our understanding of sex difference. Fergusson and Horwood (2002) concluded that offending trajectories were 
similar for males and females, however, females were more likely to follow low offending risk and early adolescent-limited pathways, while males were more likely to follow later adolescent-limited or chronic offending pathways. Piquero et al., (2005) found greater variation in male conviction experiences when compared to females, where males were more likely to be involved in, and show greater variation in criminal activity. However, their results suggested that there was a high degree of similarity between males and females in terms of the stability of offending from adolescence to early adulthood.

Few trajectory analyses have been conducted using Australian cohorts (see Marshall, 2006), with the majority of studies focusing on United Kingdom or United States samples (Piquero, 2008). This is problematic, given that the composition of offenders is likely to differ considerably across countries. There have been a number of trajectory analyses conducted using New Zealand birth and offender cohorts (for example see Fergusson \& Horwood, 2002; Piquero, Brame, \& Moffitt, 2005), although the generalisability of offending patterns identified in such research must be interpreted with caution when applied to the Australian context. International findings concerning the composition and correlates of offending trajectories are not likely to be easily generalisable to the Australian context due to socio-cultural differences, including the distribution of socioeconomic disadvantage within populations, and the status and histories of minority groups.

Juvenile offending is a pervasive problem in Australia, with about $17 \%$ to $21 \%$ of all young people having at least one officially recorded contact with the justice system (Morgan, 1993; Morgan \& Gardner, 1992; Stewart, Dennison, \& Hurren, 2006). About two-thirds of 
young people who come into contact with the justice system have one recorded contact while those with more than one reported contact account for a disproportionately large amount of offending (Cain, 1997; Carcach \& Leverett, 1999; Department of Families, Youth, and Community Care, 1998; Morgan, 1993).

There is a significant degree of continuity in criminal behaviour for those juveniles who come into contact with the justice system (Chen et al., 2005; Lynch et al., 2003). Chen et al., (2005) conducted a longitudinal investigation of recidivism based on an Australian juvenile offender cohort (New South Wales), and found that 68 percent of youths who appeared for the first time in a Children's Court in 1995 had at least one subsequent reappearance in either a juvenile or adult criminal court by the end of 2003. Additionally, higher reappearance rates were found for Indigenous people, males, and those who first appeared in court at a relatively young age (Chen et al., 2005). Similar results were found for a Queensland cohort (Lynch et al., 2003) with 79 percent of juveniles on supervised orders during 1994-95 progressing to the adult correctional system by 2002. This percentage was higher for Indigenous youths with 89 percent progressing to the adult correctional system by 2002, and 71 percent serving at least one prison term. These findings further highlight the importance of Indigenous status in examining the continuity of offending trajectories in the Australian context.

The overrepresentation of Indigenous Australians in the criminal justice system is a serious concern. In 2006, 24\% of the total Australian prisoner population were Indigenous while $2.3 \%$ of the population were Indigenous (ABS, 2006). This concern starts early with 
Indigenous young people 23 times more likely than non-Indigenous young people to spend time in juvenile detention centres (Taylor, 2006). Many social, cultural and environmental factors are proposed to explain the comparatively high rates of Indigenous offending in Australia (Broadhurst, 1997; Tyler, 1998). Prominent among these explanations are the factors of socio-economic disadvantage and socio-spatial isolation (Tyler, 1998). Strain explanations of Indigenous criminality emphasise the high rates of poverty, unemployment, poor education, and poor health that operate to constrain opportunities for Indigenous people to participate in mainstream activities (Broadhurst, 1997). Socio-economic disadvantage is likely to increase the number of developmental risk factors experienced by Indigenous individuals that may heighten the probability of following criminal trajectories. For example, socio-economic disadvantage is likely to impact on the family environment, where it may increase the probability of child maltreatment and poor parenting practices, which in turn place individuals at risk for entering offending pathways (Stewart et al., 2006; Weatherburn, Fitzgerald, \& Hua, 2003). Given the disparities between Indigenous and non-Indigenous young people in terms of socio-economic disadvantage and remoteness, which are highlighted in Table 1, these factors should be taken into account in order to disentangle the relationship between race and crime in Australia.

\section{Inset Table 1}

Cross-sectional research exploring the relationship between socio-economic status and juvenile offending indicates that offenders are more likely to have highly disadvantaged backgrounds (33\%) and are less likely to have highly advantaged backgrounds (5\%) than 
the general population (18\% and 15\% respectively) and that this disparity is much greater for Indigenous offenders (Lynch et al., 2003). While others have found a relationship between socio-economic status and delinquency in early adolescence, findings suggest that this relationship is almost entirely mediated by parental management skills (Larzelere \& Patterson, 1990; Simons, Wu, Conger, \& Lorenz, 1994). Offending has also been found to be highest in "highly accessible or very remote areas rather than those in-between" because of factors associated with location such as population size and unemployment (Carcach, 2000, p. 1).

While these findings may be used to target developmental crime prevention initiatives towards young people who are at-risk of offending, the most effective time to intervene remains unclear because focus has been on the retrospective identification of risk factors associated with entire cohorts. Developmental prevention aims to intervene at various lifephases that are linked to negative pathways such as offending (Farrington, 1994; Guerra, 1997; Johnson, 1987; Tremblay \& Craig, 1995). Intervention takes place through programs that aim to divert a person from a negative to a positive pathway. This is achieved through addressing the causes of crime via reducing the number of risk factors, which decreases a person's susceptibility to criminal behaviour, and through increasing the protective factors, which enables individuals to resist criminal behaviour in difficult situations (Farrington, 1994). Given the central role that the timing of interventions has for developmental crime prevention, it is remiss that few offending trajectory studies have been conducted in Australia. 
The current study will use the Semi-Parametric Group-based Method (SPGM) to model the juvenile offending patterns of the 1983-84 Queensland offender cohorts $(n=4,470)$ and explore three research questions: (i) How many distinct offending trajectories could be identified and what was the nature of these trajectories? (ii) How were sex, Indigenous status, socio-economic disadvantage, and remoteness related to offending trajectory membership? and (iii) Are juvenile offending trajectories predictors of adult offending? The findings of the research will improve our understanding of the nature of juvenile offending.

\section{Method}

Summary of the Offending Cohort

An offending cohort of 4,470 Queenslanders born in 1983 and 1984 with at least one finalised juvenile court appearance (ages 10-16 years) was used in the current study. In Queensland, Australia the Juvenile Justice Act 1992 defines a juvenile as a young person from the age of 10 to 17 years. Sixty percent of the cohort were non-Indigenous males. There were similar numbers of Indigenous male (17\%) and non-Indigenous female (17\%) offenders and Indigenous females made up the smallest offender group (6\%). In 2000, $48.5 \%$ of the population of 17 year olds were non-Indigenous males, $2.2 \%$ were Indigenous males, 47\% were non-Indigenous females and 2.3\% were Indigenous females (ABS, 2001). 
Offending data included all court appearances where there was a finalisation for an offence. In addition, for these young offenders, all formal police cautions were also included in the dataset. Under the Juvenile Justice Act 1992 police have the discretion to divert young people from formal processing through the courts by issuing a formal caution to young people who admit guilt. The 4,470 juvenile offenders were responsible for 11,713 court appearances and 3,920 police cautions. Over the six year period each young person had an average of 3.5 offending events, with a range from one to twenty-five. Indigenous males $(M=5.3, S D=4.3)$ and females $(M=4.1, S D=3.5)$ had more offending events than nonIndigenous males $(M=3.2, S D=2.7)$ or females $(M=2.5, S D=1.8)$.

Slightly more than one-tenth of juvenile offenders lived in areas of socio-economic disadvantage and about 5\% lived in remote areas. Nearly one-fifth of Indigenous offenders (19\%) lived in disadvantaged areas compared with $8 \%$ of non-Indigenous offenders. Likewise, Indigenous offenders were disproportionately from remote locations (15\%) when compared with non-Indigenous offenders (1\%).

\section{Dataset Linking and Cleaning}

Information on juvenile offending was obtained from two sources, Department of Families (DoF) and Queensland Police Service (QPS). The DoF dataset recorded information for each separate court appearance including the matter that the child was appearing for, whether the offence was finalised, final outcome categories, and information relating to the child such as unique identifier, date of birth, birthplace, sex, Indigenous status, and the 
statistical local area where the child lived including the suburb and postcode. Children are assigned a unique numeric identifier and 4,539 unique children were identified. However, 69 children were removed because they died prior to the age of 17 , did not reside in Queensland, or were not aged between 10 and 17 when they appeared in court.

The QPS data included all recorded police cautions for juvenile offending for young people born in 1983 or 1984 . For each caution issued information was recorded about the suburb where the caution was issued, who was responsible for issuing the caution, and the offence/s committed. While identifying information such as the young person's name, sex, and date of birth was collected there was no unique identifier. Consequently, to identify the number of police cautions any one young person had, data were sorted and manually inspected to identify and link individual young people. These data were then similarly linked to the DoF data on name, date of birth and gender.

\section{Adult offending}

Information on adult offending by people born in 1983 and 1984 was obtained from the Department of Justice and Attorney General (DJAG) and linked to the juvenile offending data based on personal information (name, sex, and date of birth). This linking was carried out in 2001 when the juvenile offender cohorts were 19 or 20 years old. Consequently the young offenders had between two and four years to re-offend as adults depending on their date of birth. The young offenders were assigned a 'yes' or 'no' value for adult offending based on whether they had a finalised court appearance in the adult system. A comparison 
of the adult offending rates of juvenile offenders born in 1983 and those born in 1984 suggested that the impact of these differences in follow-up time was minimal. Just over one-third of the 1983 (37\%) and 1984 (41\%) cohorts had progressed to adult offending.

Remoteness of residence and socio-economic disadvantage

Remoteness of residence and socio-economic disadvantage were based on the Statistical Local Area (SLA) where the juvenile resided at the time of their finalised court appearance (based on the DoF dataset) or the suburb where cautions were issued (based on the QPS dataset). The remoteness of SLAs was based on the Accessibility and Remoteness Index of Australia (ARIA) that provides a level of accessibility ranging from one to five (highly accessible to very remote) (ABS, 2001). Socio-economic disadvantage was based on the Index of Relative Socio-Economic Disadvantage (IRSED) that provides a continuous value for socio-economic disadvantage for suburbs (ABS, 2001). These indices have been used in a large number of other research projects and are widely regarded as a valid measure of the social phenomena they represent (see for example, Carcach, 2000; Lynch et al., 2003).

Assigning a single value for remoteness and socio-economic disadvantage was straightforward for offenders who resided in the same SLA or had the same suburb for each of their contacts with the justice system. However, aggregate values for these two indices had to be produced for offenders who resided over time in more than one SLA or suburb. As the IRSED is a continuous value, an average value of the index was created to reflect the different locations where young people resided over the course of their juvenile 
offending histories. As the ARIA only provided a categorical level of remoteness, offenders were assigned a remoteness level based on whichever level was most common over their offending career. To simplify the analysis, these two measures were transformed into binary variables so that each young person was classified as 'remote' or 'not remote' and 'disadvantaged' or 'not disadvantaged'.

\section{Model Selection}

The Semi-Parametric Group-based Method (SPGM) was used to develop models of the distinct offending trajectories for the 4,470 offenders in the cohort. The SPGM analysis was undertaken using the SAS procedure TRAJ developed by Jones, Nagin, and Roeder (2001). As the majority of young people in the cohort offended for only short periods of time, there was an excess of data cells with zero counts for offending. Because of this, the offending count data was distributed according to the Zero-Inflated Poisson distribution (ZIP) (Fergusson et al, 2000; Nagin, 1999). This distribution can simply be defined as a standard Poisson distribution with a greater number of zeros than would normally be expected.

Due to the non-parametric nature of the procedure being used, it was necessary to specify the number of trajectory groups being modelled and the form of these trajectories (i.e.: cubic, quadratic, linear, etc) prior to analysis. In other words, the SPGM method does not determine the number of distinct classes of trajectories, rather this is assumed a priori. Further, it was also necessary to specify the form of the trajectories prior to developing the models. Thus, the development of the final model was necessary iterative, with the process 
being repeated a number of times to determine the parameters (i.e.: the number of trajectories and their forms) that produced the best fit for the data.

The final number of trajectories for the model was based on both the Bayesian Information Criteria (BIC) and the average probability of assignment. The BIC increases as the model fit improves (incorporating the penalty for increases in the number of trajectories) while the average probability of assignment is higher for models with more distinct trajectories. Thus, the model with the optimum number of trajectories needed to have a high BIC (relative to other model options) and an average probability of group membership that was as close to one as possible. 


\section{Results}

The first research question sought to determine how many distinct offending trajectories could be identified in the criminal careers of young offenders and the nature of these trajectory groups. Models with between two and six trajectories were created and the BIC and average group membership probabilities for each of these models were examined. It was evident that the optimal model included either three $(\mathrm{BIC}=-24,764, p=0.82)$ or four (BIC $=-24,743, p=0.73)$ groups. The four-group model provided the highest (i.e.: least negative) value for the BIC, while the three-group model had a relatively high value for BIC and a substantially higher average probability of group membership. The model with the smaller number of groups was selected for ease of interpretation (Fergusson et al., 2000). Thus, all further analyses were conducted under the assumption that the optimum trajectory model had three distinct groups of trajectories.

It was then necessary to ascertain the form of the three trajectories. The results of the SPGM provided estimates for each component (i.e.: cubic, quadratic, linear, and intercept terms) of each trajectory. The results also specify which of these terms was significant in the model. For each of the three trajectories developed, all terms bar one were significant in the model at the 0.1 level (eight of the 12 items were significant at the 0.05 level) and all trajectories had a significant cubic term (Table 2). Therefore, it was reasonable to assume that the three trajectories were best described by cubic functions.

Insert Table 2 
The model identified three distinct offending groups (Figure 1). Group one showed an early onset of offending, with a peak around the age of 14 followed by a decline into later adolescence. This group included about one-fifth of the cohort (21\%) who were responsible for $23 \%$ of the offences committed by the cohort, averaging 3.9 offending incidents each. Group one was labelled 'Early peaking-moderate offenders', since their offending appeared to plateau in adolescence with a decreasing trend towards the end of the follow-up period. Group two had little or no evidence of offending behaviour in the early teen years with a gradual increase up until the age of sixteen. This was the largest group of offenders and included over two-thirds of the sample (68\%) who were responsible for $44 \%$ of the cohort's offending, averaging 2.3 offending incidents each. Group two was labelled 'Late onsetmoderate offenders' as their offending began at a comparatively later age and continued to increase through later adolescence. The third group demonstrated an early onset of offending with a sharp increase throughout the time-frame. This was the smallest of the cohorts identified by the model, containing $11 \%$ of offenders, who were responsible for about a third (33\%) of offending by the cohort, averaging 11 offending incidents each. Group three was labelled 'Chronic offenders'.

\section{Insert Figure 1}

The second research question explored whether sex, Indigenous status, socio-economic disadvantage, and remoteness were related to offending trajectory membership. Univariate analyses were conducted to determine whether trajectory group membership was 
independently related to each of these four factors to determine which factors should be included in the multinominal logistic regression (Table 3). Results indicated that sex, Indigenous status, and socio-economic disadvantage were related to offending trajectory group membership while remoteness was not related to group membership.

Insert Table 3

One multinominal logistic regression was then performed using sex (male/female), Indigenous status (Indigenous or non-Indigenous), and socio-economic disadvantage (disadvantaged or not disadvantaged) as the independent variables and group membership (Early peaking-moderate offenders, Late onset-moderate offenders and Chronic offenders) as the dependent variable. The proportion of variance in group membership accounted for using these factors was small (6\%) and the classification accuracy of the model was 68.4\%. The parameter estimates for the multinominal model are displayed in Table 4, which compares group one (Early peaking- moderate offenders) and group two (Late onsetmoderate offenders) with group three (Chronic Offenders).

Insert Table 4

Indigenous status and sex were related to group membership and after these factors were controlled for, socio-economic disadvantage was no longer significantly related to group 
membership. Indigenous offenders were 4.7 times more likely than non-Indigenous offenders to be Chronic Offenders rather than Late onset-moderate offenders and 3.1 times more likely to be Chronic Offenders than Early peaking-moderate offenders. Male offenders were more than twice as likely as female offenders to be members of the Chronic Offending group than either of the two other groups.

The third research question explored whether the trajectories fitted by the model predicted adult offending. One chi-square analysis was performed that explored the association between group membership (independent variable) and whether offenders had a finalised adult court appearance (dependent variable). Findings indicated that Chronic Offenders were around twice as likely as offenders in either of the other two offending groups to have a finalised adult court appearance $(\chi 2=188.13, N=4,470, d f=2, p<0.001)$. More than two-thirds (67\%) of Chronic Offenders had recorded adult offences in the follow up period, compared with 33\% of Early peaking-moderate offenders and 36\% of Late onset-moderate offenders (Table 5).

Insert Table 5

\section{Discussion}

The present research is one of the few Australian studies to employ a trajectory analysis methodology using an offender cohort. Largely consistent with international offending trajectory studies, the present study identified three distinct offending patterns within the 
Queensland 10 through 17 years old offender cohort. The three trajectories displayed key differences in the shape and rate of annual offences across time. The trajectories were labelled “Early peaking-moderate offending' (21\% of the cohort), Late onset-moderate offending' (68\% of the cohort) and 'Chronic Offending' (11\% of the cohort). Betweengroup differences were observed in offence trajectories and the predictive utility of the covariates of Indigenous status and sex on trajectory group membership. Specifically, both Indigenous and male offenders were more likely than non-Indigenous and female offenders to be in the Chronic Offenders group. This result highlights the importance of sex and race in understanding the development of offending within the Australian context, and supports the findings of Marshall (2006), who found Indigenous and male youths to be highly overrepresented in trajectory groups characterised by moderate to high frequency, early onset and serious offending.

These results are very similar to those identified in the review of trajectory analyses studies conducted by Piquero (2008). In support of Moffit's (1993) theorising that there are two distinct types of offenders, this study identified a group that appears to be adolescent limited (Early peaking-moderate offenders), in that their offending began in early adolescence, peaked around 14 years of age, and appeared to decline in later adolescence, and comprised about one-fifth (21\%) of the offending cohort. Also identified was an early onset Chronic Offenders group, which comprised one-tenth (11\%) of young people who offended. As with previous research, this small group of habitual chronic offenders was found to be responsible for a considerable amount (33\%) of the cohort's offending. Given the shape of the chronic offending trajectory and the high proportion of this group (67\%) 
who offended as adults during the follow-up period, the findings are consistent with Moffit's (1993) proposition that early onset of offending is an indicator of persistent offending and that a small group of life-course persistent offenders are responsible for a large proportion of offending.

The chronic trajectory comprised $11 \%$ of the total offender cohort, or $0.44 \%$ of all individuals born in Queensland in 1983-84. This finding does not conform with previous offending trajectory studies using birth cohorts, which on average tend to find chronic offending trajectories comprised of between 5 to $15 \%$ of the total cohort (for example, D’Unger et al., 1998). However, studies using official records (convictions) as the dependent variable appear to classify lower population proportions as chronic offenders. For example, results from analysis of the 1972 birth cohort from Dunedin, New Zealand, indicated that the highest offending frequency latent class comprised less than one percent of the population (Piquero et al., 2005). It is likely that the proportion of individuals identified as chronic offenders in trajectory analyses depends partly on the nature of the cohort (birth versus offender cohort), as well as the measure of offending (official versus self-report measures).

Consistent with the late onset chronic group (late onset-moderate offenders) identified by Piquero (2008) this study also identified a third offending group. This group commenced offending at the age of 15 and 33\% of them continued on into adulthood. Further trajectory analysis with data that continues past the age of 16 is required to confirm this group. The existence of this group is not consistent with Moffitt's (1993) developmental taxonomy of 
offenders or other developmental theories (Chung et al., 2002; D’Unger et al., 1998; Fergusson \& Horwood, 2002; Marshall, 2006; Silverthorn et al., 2001). The observation of a late onset group of offenders in the present study further highlights the need for criminological theory and research to explain the developmental processes underlying the offending of the individuals predicted to be within this trajectory.

The design of the present study did not allow for an examination of the explanatory validity of population heterogeneity and state dependence explanations of continuity in criminal offending. That is, time-stable and time-varying individual characteristics were not measured in the present study. However, the present results did indicate that there was a substantial degree of continuity in criminal behaviour from early adolescence to late adolescence and early adulthood as measured by official court appearance data. It is likely that the present study would have displayed strong support for the population heterogeneity position if time-stable and time-varying characteristics were measured, as Nagin and Paternoster (2000) report that high-risk samples based on official data are more likely to show strong evidence in support of such a position.

Consequently, the results of the present study may be interpreted as providing tentative support to the DLC assumption that different offence patterns may be explained by unique causal processes, where offenders differ in kind as well as degree. For example, evidence from the present study indicated that the composition of the groups differed significantly according to the covariates of sex and Indigenous status. While this does not directly indicate that different etiological processes operate across different offending groups, it 
suggests that certain individuals experience greater levels of risk or may be more susceptible to developmental processes leading to offending behaviour.

Despite the important findings of the current study, the research should be interpreted in light of four main limitations. First, the study used official records (cautioning and finalised court appearances) to measure offending. Therefore, it may only represent a fraction of actual offending that comes to the attention of justice agencies, may represent more serious cases, and may over-represent those with a low socio-economic status due to biases in agency activity (Brown, 1984; Widom, 1989). Second, the trajectory model developed in the current study was based on a relatively small age range (10 to 16) when compared to other studies. While the interaction that these young people have had with the justice system may be accurately approximated based on offence histories, whether these groups will remain in the future with the addition of adult appearance data remains a matter for speculation (D’Unger et al., 1998). Piquero (2008) emphasises that the number of latent offending groups identified is likely to vary according to the time span of a study, where longer study periods yield more trajectories. This may help explain why the current study found only three groups, since the sample was only followed up to 17 years. Furthermore, the limited age range likely contributed to the observation that only one group identified in the present study (Early peaking-moderate offending) displayed a trend toward desistence. Previous longitudinal research indicates that most offenders appear to be on a trajectory toward desistance from criminal activity (Piquero et al, 2002; Piquero, Farrington, \& Blumstein, 2007). The current study period did not cover the early 20s, which is where desistance processes appear to be in operation (Farrington, 2003a; Piquero et al., 2007). 
Future research on the present cohort should attempt to examine the processes of desistance as offenders enter early adulthood.

Third, the study could not fully take into account attrition of the sample through death or population mobility. It is likely that there were a number of people in the cohort who died or moved outside of Queensland and were included in the final trajectory model. Evidence suggests that taking into account cohort sample attrition may result in some variation in the final model that is identified (Eggleston et al., 2004). Finally, the current study did not control for the effects exposure time, the amount of time that an individual is restricted from engaging in criminal behaviour in public due to incapacitation, which has been argued to be essential in calculating unbiased estimates of individual rates of offending (Piquero et al., 2001). However, in Queensland, young offenders are rarely incarcerated and are incarcerated for short periods of time. The average number of young people in detention at any one time is 150 young people and the average length of time in custody is less than three months. Earlier investigation found negligible effects of incapacitation on rate of offending (Stewart, Spencer, O’Connor, Palk, Livingston \& Allard, 2004).

While further studies are required to develop tools more capable of prospectively (rather than retrospectively) identifying chronic offenders, the findings of the current study highlight the crucial importance of the early years of life and the need to target crime prevention initiatives towards the chronic offending group, as this is likely to result in significant reductions in crime. This study should therefore provide a starting point by alerting policy makers to the existence of a small group of offenders that pose the largest 
long-term concern for the justice system. This small group has an early onset of delinquency, engage in criminal activity over the entirety of their teenage years, and are more likely to be Indigenous and male. The results of this study represent an initial step towards modelling the offence patterns of Australian offenders and identifying those individuals to which developmental interventions may be most effectively targeted to prevent future offending.

\section{$\underline{\text { Acknowledgments }}$}

The authors would like to thank the Department of Families (renamed the Department of Communities), Queensland Police Service, and Department of Justice and Attorney General for the assistance they provided with this project. 


\section{References}

ABS (Australian Bureau of Statistics). (2006). Census of Population and Housing. Canberra: Australian Bureau of Statistics.

ABS (Australian Bureau of Statistics). (2001). Australian Census of Population and Housing - Indigenous Community Profiles: Queensland. Canberra: Australian Bureau of Statistics.

Blumstein, A., Cohen, J., Roth, J., \& Visher (Eds.). (1986). Criminal Careers and "Career Criminals". Report of the National Academy of Sciences Panel on Research on Criminal Careers. Washington, D.C.: National Academy Press.

Blumstein, A., Cohen, J., \& Farrington, D. (1988). Longitudinal and Criminal Career Research: Further Clarifications. Criminology, 26, 57-74.

Brame, R., Bushway, S.D., Paternoster, R., \& Thornberry, T.P. (2005). Temporal Linkages in Violent and Nonviolent Criminal Activity. Journal of Quantitative Criminology, 21(2), 149-174.

Broadhurst, R. (1997). Aborigines and Crime in Australia. In M. Tonry (Ed.), Ethnicity, Crime, and Immigration: Comparative and Cross-National Perspectives. Crime and Justice: A Review of Research (Vol. 21, pp. 407-468). Chicago: University of Chicago Press.

Broidy, L.M., Nagin, D.S., Tremblay, R.E., Bates, J.E., Brame, B., Dodge, K.A., Fergusson, D., Horwood, J.L., Loeber, R., Laird, R., Lynam, D.R., Moffitt, T.E., Pettit, G.S., \& Vitaro, F. (2003). Developmental Trajectories of Childhood Disruptive Behaviors and Adolescent Delinquency: A Six-Site, Cross-National Study. Developmental Psychology, 39(2), 222-245. 
Brown, S. (1984). Social Class, Child Maltreatment, and Delinquent Behavior. Criminology, 22 (2), 259 - 278.

Cain, M. (1997). An Analysis of Juvenile Recidivism. Paper Presented at: Australian Institute of Criminology Conference, Juvenile Crime and Juvenile Justice: Toward 2000 and Beyond, Adelaide 26-27 June 1997.

Carcach, C. (2000). Size, Accessibility and Crime in Regional Australia. Trends and Issues in Crime and Criminal Justice, No. 175. Canberra: Australian Institute of Criminology.

Carcach, C., \& Leverett, S. (1999). Recidivism Among Juvenile Offenders: An Analysis of Times to Reappearance in Court. Canberra: Australian Institute of Criminology.

Cernkovich, S.A., \& Giordano, P.C. (2001). Stability and Change in Antisocial Behavior: The Transition from Adolescence to Early Adulthood. Criminology, 39(2), 371-410.

Chen, S., Matruglio, T., Weatherburn, D., \& Hua, J. (2005). The Transition from Juvenile to Adult Criminal Careers. Crime and Justice Bulletin: Contemporary Issues in Crime and Justice, Number 86. NSW Bureau of Crime Statistics and Research.

Chung, I.J., Hill, K.G., Hawkins, J.D., Gilchrist, L.D., \& Nagin, D.S. (2002). Childhood Predictors of Offence Trajectories. Journal of Research in Crime and Delinquency, 39(1), 60-90.

D’Unger, A., Land, K., McCall, P. \& Nagin, D. (1998). How Many Latent Classes of Delinquent/Criminal Careers? Results from Mixed Poisson Regression Analyses. American Journal of Sociology, 103, 1593-1630.

Department of Families, Youth, and Community Care. (1998). Juvenile Offending and Recidivism in Queensland. Queensland: Juvenile Justice Branch. 
Eggleston, E., Laub, J., \& Sampson, R. (2004). Methodological Sensitivities to Latent Class Analysis of Long-Term Criminal Trajectories. Journal of Quantitative Criminology, 20(1), 1-26.

Elder, G.H., Jr. (1994). Time, Human Agency, and Social Change: Perspectives on the Life Course. Social Psychology Quarterly, 57(1), 4-15.

Ezell, M.E. (2007). The Effect of Criminal History Variables on the Process of Desistance in Adulthood Among Serious Youthful Offenders. Journal of Contemporary Criminal Justice, 23(1), 28-49.

Farrington, D.P. (2003a). Key Results from the First Forty Years of the Cambridge Study in Delinquent Development. In Thornberry TP \& Krohn M (eds), Taking Stock of Delinquency: An Overview of Findings from Contemporary Longitudinal Studies. New York: Kluwer: 137-184.

Farrington, D.P. (2003b). Developmental and Life-Course Criminology: Key Theoretical and Empirical Issues - The 2002 Sutherland Award Address. Criminology, 41(2), 221-255.

Farrington, D. (1994). Early Developmental Prevention of Juvenile Delinquency. Criminal Behaviour and Mental Health, 4, 209-226.

Farrington, D. P., \& West, D.J. (1990). The Cambridge Study in Delinquent Development: A Long-Term Follow-Up of 411 London Males. In H.J. Kerner and G. Kaiser (Eds.). Criminality: Personality, Behaviour, Life History. Berlin: Springer-Verlag.

Fergusson, D \& Horwood, L. (2002). Male and Female Offending Trajectories. Development and Psychopathology, 14, 159-177. 
Fergusson, D., Horwood, L., \& Nagan, D. (2000). Offending Trajectories in a New Zealand Birth Cohort. Criminology, 38(2), 525-551.

Francis, B., Soothill, K., \& Fligelstone, R. (2004). Identifying Patterns and Pathways of Behaviour: A New Approach to Typologies of Crime. European Journal of Criminology, 1(1), 47-87.

Gottfredson, M., \& Hirschi, T. (1990). A General Theory of Crime. Stanford, CA: Stanford University Press.

Guerra, N. (1997). Intervening to Prevent Childhood Aggression in the Inner City. In McCord, J (ed) Violence and Childhood in the Inner City. Cambridge: Cambridge University Press.

Johnson, E. (1987). Handbook on Crime and Delinquency Prevention. New York: Greenwood Press.

Jones, B., Nagin, D. \& Roeder, K. (2001). A SAS Procedure Based on Mixture Models for Estimating Developmental Trajectories. Sociological Methods and Research, 29(3), 374-393.

Juvenile Justice Act, 1992, (QLD).

Kokko, K., Tremblay, R.E., Lacourse, E., Nagin, D.S., \& Vitaro, F. (2006). Trajectories of Prosocial Behavior and Physical Aggression in Middle Childhood: Links to Adolescent School Dropout and Physical Violence. Journal of Research on Adolescence, 16(3), 403-428.

Kreuter, F., \& Muthén, B. (2008). Analyzing Criminal Trajectory Profiles: Bridging Multilevel and Group-based Approaches Using Growth Mixture Modeling. Journal of Quantitative Criminology, 24, pp. 1-31. 
Larzelere, R., \& Patterson, G. (1990). Parental Management: Mediator of the Effect of Socio-Economic Status on Early Delinquency. Criminology, 28(2), pp 301-323.

Lynch, M., Buckman, J. \& Krenske, L. (2003). Youth Justice: Criminal Trajectories. Trends and Issues in Criminal Justice, No. 265. Canberra: Australian Institute of Criminology.

Marshall, J. (2006). Juvenile Offending Trajectories: A South Australian Study. South Australia: Office of Crime Statistics and Research.

Moffitt, T.E. (2006). Life-Course-Persistent versus Adolescence-Limited Antisocial Behavior. In D. Cicchetti \& D.J. Cohen (Eds.), Developmental Psychopathology. ( $2^{\text {nd }}$ ed., Vol. 3, pp.570-598). Newark: John Wiley \& Sons, Inc..

Moffitt, T.E. (1997). Adolescence-Limited and Life-Course-Persistent Offending: A Complementary Pair of Developmental Theories. In T.P. Thornberry (Ed.), Developmental Theories of Crime and Delinquency: Advances in Criminological Theory. (Vol. 7, pp. 11-54). New Jersey: Transaction Publishers.

Moffitt, T.E. (1993). Life-Course Persistent and Adolescence-Limited Anti-Social Behaviour: A Developmental Taxonomy. Psychological Review, 100, 674-701.

Morgan, F. (1993). Contact with the Juvenile System Over the Juvenile Years. Paper Presented at: National Conference on Juvenile Justice: Proceedings of a Conference held 22-24 September 1992. Canberra: Australian Institute of Criminology.

Morgan, F., \& Gardner, J. (1992). Juvenile Justice. Adelaide, South Australia: Office of Crime Statistics, Attorney-General’s Department. 
Muthén, B.O., \& Muthén, L.K. (2000). Integrating Person-Centered and Variable-Centered Analyses: Growth Mixture Modeling with Latent Trajectory Classes. Alcoholism: Clinical and Experimental Research, 24, 882-891.

Nagin, D. (1999). Analyzing Developmental Trajectories: A Semiparametric, Group-Based Approach. Psychological Methods, 4(2), 139-157.

Nagin, D. \& Land, L. (1993). Age, Criminal Careers, and Population Heterogeneity: Specification and Estimation of a Nonparametric, mixed Poisson model. Criminology, 31(3), 327-362.

Nagin, D., \& Paternoster, R. (2000). Population Heterogeneity and State Dependence: State of the Evidence and Directions for Future Research. Journal of Quantitative Criminology, 16(2), 117-144.

Nagin, D., \& Tremblay, R. (2005). What Has Been Learned from Group-Based Trajectory Modelling? Examples from Physical Aggression and other Problem Behaviours. The Annals of the American Academy of Political and Social Sciences, 602, 82-117.

Nagin, D., \& Tremblay, R.E. (1999). Trajectories of Boy’s Physical Aggression, Opposition, and Hyperactivity on the Path to Physically Violent and Nonviolent Juvenile Delinquency. Child Development, 70(5), 1181-1196.

National Crime Prevention. (1999). Pathways to Prevention: Developmental and Early Intervention Approaches to Crime in Australia. Canberra: Australian Government Publishing Service. Available online at http://www.ag.gov.au.

Paternoster, R., Dean, C.W., Piquero, A.R., Mazerolle, P., \& Brame, R. (1997). Generality, Continuity, and Change in Offending. Journal of Quantitative Criminology, 13(3), 231-266. 
Piquero, A.R. (2008). Taking Stock of Developmental Trajectories of Criminal Activity Over the Life Course. In A. Liberman (Ed.) The Long View of Crime: A Synthesis of Longitudinal Research. New York: Springer. (pp. 23 -78)

Piquero, A.R., Blumstein, A., Brame, R., Haapanen, R., Mulvey, E.P., \& Nagin, D. (2001). Assessing the Impact of Exposure Time and Incapacitation on Longitudinal Trajectories of Offending. Journal of Adolescent Research, 16(1), 54-74.

Piquero, A.R., Brame, R., \& Moffitt, T.E. (2005). Extending the Study of Continuity and Change: Gender Differences in the Linkage Between Adolescent and Adult Offending. Journal of Quantitative Criminology, 21(2), 219-243.

Piquero, A.R., Brame, R., Mazerolle, P., \& Haapanen, R. (2002). Crime in Emerging Adulthood. Criminology, 40(1), 137-169.

Piquero, A.R., Farrington, D.P., \& Blumstein, A. (2007). Key Issues in Criminal Career Research: New Analyses of the Cambridge Study in Delinquent Development. Cambridge: Cambridge University Press.

Piquero, A., Farrington, D., \& Blumstein, A. (2003a). The Criminal Career Paradigm: Background and Recent Developments. Crime and Justice: A Review of Research, 30, 359-506.

Sampson, R.J., \& Laub, J.H. (2005). A Life-Course View of the Development of Crime. The Annals of the American Academy, 602, 12-45.

Sampson, R.J., \& Laub, J.H. (2003). Life-Course Desisters? Trajectories of Crime Among Delinquent Boys Followed to Age 70. Criminology, 41(3), 301-340.

Sampson, R.J., \& Laub, J.H. (1993). Crime in the Making: Pathways and Turning Points Through Life. Cambridge, MA: Harvard University Press. 
Silverthorn, P., Frick, P.J., \& Reynolds, R. (2001). Timing of Onset and Correlates of Severe Conduct Problems in Adjudicated Girls and Boys. Journal of Psychopathology and Behavioral Assessment, 23(3), 171-181.

Simons, R., Wu, C., Conger, R., \& Lorenz, F. (1994). Two Routes to Delinquency: Differences Between Early and Late Starters in the Impact of Parenting and Deviant Peers. Criminology, 32(2), $247-275$.

Stewart, A., Dennison, S., \& Hurren, E. (2006). Juvenile Offending Trajectories: Pathways from Child Maltreatment to Juvenile Offending and Police Cautioning in Queensland. Report to the Criminological Research Council, Grant 35/03-04.

Stewart, A., Spencer, N., O’Connor, I., Palk, G., Livingston, M., \& Allard, T. (2004). Juvenile Justice Simulation Model: A Report on the Australian Research Council Strategic Partnerships with Industry Research and Training Grant No C00106983.

Taylor, N. (2006). Juveniles in Detention in Australia, 1981-2005 (Technical and Background Paper No. 22). Canberra: Australian Institute of Criminology.

Thornberry, T.P. (2005). Explaining Multiple Patterns of Offending Across the Life Course and Across Generations. The Annals of the American Academy, 602, 156-195.

Tremblay, R., \& Craig, W. (1995). Developmental Crime Prevention. In M. Tonry, \& D. Farrington (Eds). Strategic Approaches to Crime Prevention: Building a Safer Society. Chicago: The University of Chicago Press.

Tyler, W. (1998). Race, Crime and Region: The Socio-Spatial Dynamic of Aboriginal Offending. Journal of Sociology, 34(2), 152-169.

Weatherburn, D., Fitzgerald, J., \& Hua, J. (2003). Reducing aboriginal over-representation in prison. Australian Journal of Public Administration, 67(3), 65-73. 
Widom, C. S. (1989). Child Abuse, Neglect, and Violent Criminal Behavior. Criminology, 27(2), $251-271$.

Wiesner, M., Kim, H.K., \& Capaldi, D.M. (2005). Developmental Trajectories of Offending: Validation and Prediction to Young Adult Alcohol Use, Drug Use, and Depressive Symptoms. Development and Psychopathology, 17, 251-270.

Williams, R.K., \& Arnold, B.L. (2002). Offence Specialization Among Serious Habitual Juvenile Offenders in a Canadian City During the Early Stages of Criminal Careers. International Criminal Justice Review, 12, 1-21. 
Table 1: Social and economic indicators from 2001 Census by Indigenous status, Queensland (ABS, 2001)

\begin{tabular}{lcc}
\hline & Indigenous & Non-Indigenous \\
\hline Median weekly income & $\$ 600-\$ 699$ & $\$ 800-\$ 899$ \\
Unemployment rate & $20 \%$ & $8 \%$ \\
$\%$ completed grade 10 & $60 \%$ & $48 \%$ \\
$\%$ with university qualifications & $2 \%$ & $10 \%$ \\
$\%$ households living in public housing & $30 \%$ & $2 \%$ \\
$\%$ living in very remote regions & $15 \%$ & $1 \%$ \\
\hline
\end{tabular}


Table 2: Significance of parameter estimates for final trajectory model

\begin{tabular}{lll}
\hline Group & Parameter & p-value \\
\hline & Intercept & 0.06 \\
Linear & 0.02 \\
& Quadratic & $<0.01$ \\
& Cubic & $<0.01$ \\
\hline & Intercept & 0.01 \\
Lroup One & $<0.01$ \\
& Quadratic & $<0.01$ \\
& Cubic & $<0.01$ \\
\hline Intercept & 0.12 \\
\hline & Linear & 0.06 \\
& Quadratic & 0.03 \\
& & 0.02 \\
\hline
\end{tabular}


Figure 1: Three group trajectory model of offending for Queensland offenders born in 1983 or 1984

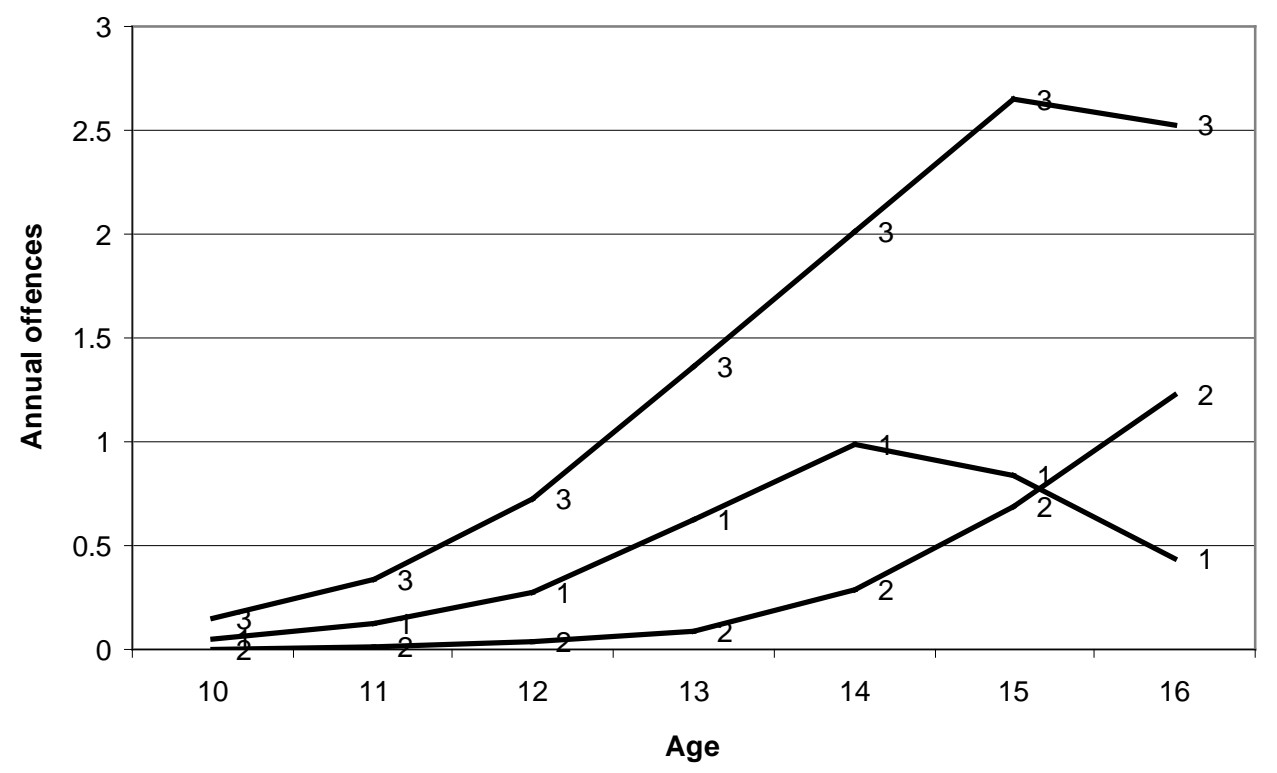

Group 1 - Early peaking-moderate offenders

Group 2 - Late onset-moderate offenders

Group 3 - Chronic offenders 
Table 3: Offending trajectory group membership by sex, Indigenous status, remoteness and socio-economic disadvantage.

\begin{tabular}{|c|c|c|c|c|c|c|c|}
\hline & \multicolumn{6}{|c|}{ Offending trajectory } & \multirow[b]{5}{*}{$\chi^{2}$} \\
\hline & \multirow{3}{*}{\multicolumn{2}{|c|}{$\begin{array}{c}\text { Early peaking } \\
\text { moderate } \\
\text { offenders }\end{array}$}} & \multirow{3}{*}{\multicolumn{2}{|c|}{$\begin{array}{c}\text { Late peaking } \\
\text { moderate } \\
\text { offenders }\end{array}$}} & \multirow{3}{*}{\multicolumn{2}{|c|}{$\begin{array}{l}\text { Chronic } \\
\text { offenders }\end{array}$}} & \\
\hline & & & & & & & \\
\hline & & & & & & & \\
\hline & $n$ & $\%$ & $n$ & $\%$ & $n$ & $\%$ & \\
\hline \multicolumn{8}{|l|}{ Sexr } \\
\hline Male & 701 & 20.4 & 2317 & 67.3 & 425 & 12.3 & \\
\hline Female & 222 & 21.6 & 741 & 72.2 & 64 & 6.2 & $30.35^{* * *}$ \\
\hline \multicolumn{8}{|l|}{ Indigenous status } \\
\hline Indigenous & 234 & 22.4 & 562 & 53.8 & 249 & 23.8 & \\
\hline Non-Indigenous & 689 & 20.1 & 2496 & 72.9 & 240 & 7.0 & $251.77 * * *$ \\
\hline \multicolumn{8}{|l|}{ Remoteness } \\
\hline Accessible & 875 & 20.5 & 2932 & 68.7 & 459 & 10.8 & \\
\hline Remote & 48 & 23.5 & 126 & 61.8 & 30 & 14.7 & 5.01 \\
\hline \multicolumn{8}{|l|}{ SES disadvantage } \\
\hline Advantaged & 825 & 20.7 & 2753 & 69.0 & 414 & 10.4 & \\
\hline Disadvantaged & 98 & 20.5 & 305 & 63.8 & 75 & 15.7 & $12.71^{*}$ \\
\hline$p<.05$ & & & & & & & \\
\hline *** $\quad p<.001$ & & & & & & & \\
\hline
\end{tabular}


Table 4: Multinomial logistic regression analysis of offending trajectory group

membership as a function of sex, Indigenous status and socio-economic disadvantage (base reference group is Chronic offenders).

\begin{tabular}{|c|c|c|c|c|c|c|c|}
\hline \multirow{2}{*}{ Comparison } & \multirow{2}{*}{ B } & \multirow{2}{*}{ S.E. } & \multirow{2}{*}{ Wald } & \multirow{2}{*}{ D.f. } & Odds & \multicolumn{2}{|c|}{$95 \%$ CI } \\
\hline & & & & & ratio & Lower & Upper \\
\hline \multicolumn{8}{|l|}{ Early peaking-moderate offenders } \\
\hline Non Indigenous V Indigenous & 1.114 & 0.12 & $89.8^{* * *}$ & 1 & 3.13 & 2.47 & 3.96 \\
\hline Male V Female & -0.832 & 0.16 & $28.2^{* * *}$ & 1 & 0.44 & 0.32 & 0.59 \\
\hline S.E. advantage $\mathrm{V}$ disadvantage & 0.162 & 0.17 & 0.9 & 1 & 1.18 & 0.84 & 1.64 \\
\hline Constant & 0.463 & 0.21 & $5.0 *$ & 1 & & & \\
\hline
\end{tabular}

Late onset-moderate offenders

Non Indigenous V Indigenous

$\begin{array}{lllllll}1.554 & 0.10 & 222.7^{* * *} & 1 & 4.73 & 3.86 & 5.80\end{array}$

Male V Female

$-0.866$

$0.1436 .1^{* * *}$

$1 \quad 0.42$

0.32

0.56

S.E. advantage V disadvantage

0.151

0.15

1.1

1

1.16

0.87

1.56

Constant

1.372

0.18

$55.7^{* * *}$

1 
Table 5 Offending as an adult by adolescent offending trajectory group membership

\begin{tabular}{lcccc}
\hline & \multicolumn{4}{c}{ Adult Offending } \\
\cline { 2 - 5 } & \multicolumn{3}{c}{ Yes } & \multicolumn{2}{c}{ No } \\
\cline { 2 - 5 } Offending trajectory & $n$ & $\%$ & $n$ & $\%$ \\
& 308 & 33.4 & 615 & 66.6 \\
Early peaking moderate offenders & 1102 & 36.0 & 1956 & 64.0 \\
Late peaking moderate offenders & 329 & 67.3 & 160 & 32.7 \\
Chronic offenders & & & & \\
\hline
\end{tabular}

